\title{
SORPTION OF HYDROCARBONS ON PEAT, AND POSSIBILITIES FOR USING PEAT-BASED OIL SORBENT FOR TREATMENT OF POLLUTED AREAS
}

\author{
Dmitry Porshnov \\ Maris Klavins \\ University of Latvia, Latvia
}

\begin{abstract}
The growing use and transport of crude oil and oil products has led to an increasing amount of spillages of various scales. In the event of an oil spill, it is important to stop the spill from spreading and to clean up the polluted environment. One of the possible ways of treating the polluted areas is the use of oil sorbents. The sorbents used for collecting oil in case of oil spills are mostly synthetic, which limits the possibilities of their disposal. The aim of our study is to investigate the possible use of peat and its modification products for oil and other hydrocarbon sorption. Peat is a prospective material for oil sorption because it has such advantages as low cost, biodegradability and relatively high parameters of specific surface area and porosity. At the same time, peat also has disadvantages, such as poor buoyancy characteristics, relatively low oil sorption capacity and low hydrophobicity.

We have studied the sorption characteristics of native high-moor peat with different botanical compositions and levels of decomposition, as well as the effect of thermal treatment on the oil sorption capacity, buoyancy and water sorption capacity of peat in comparison with the effect achieved by means of two other methods of chemical modification: silylation and methylation. We have determined the optimal conditions for thermal modification of peat to have an effect on hydrocarbon sorption characteristics. Using the method of IR spectroscopy, we have investigated specific structural changes in peat, which resulted in the improvement of its sorptive characteristics.
\end{abstract}

\section{KEYWORDS}

Peat, oil, sorbent, thermal treatment, methylation, silylation, IR spectroscopy

\section{INTRODUCTION}

Oil and its products are a widespread and very dangerous environmental pollutant group. The growth of energy consumption and industrial production inevitably increases the volume of oil extraction, transportation and consumption and thus also the risk of oil spillage and resultant environmental pollution [1]. Since this risk is now considered as imminent, technologies and materials that help to minimise or eliminate the environmental impact caused by oil contamination are very important. If oil and its products are spilled in aquatic or terrestrial environments, it is very important to take urgent action to stop the contamination from spreading and to collect as much of the discharged products as possible. One of the most

https://doi.org/10.15626/Eco-Tech.2010.109 
effective methods for this purpose is the use of oil sorbents. Sorbents are substances that can bind oil hydrocarbons as a result of absorption and/or adsorption processes. Some requirements for a good sorbent include high hydrophobicity, high sorption capacity, buoyancy, porosity and high specific surface area. A significant advantage of a sorbent is its biodegradation capability [2].

Raised bog peat with a low degree of decomposition can be considered as a prospective material for oil sorption [3]. This peat is characterised by a developed, complex pore system due to its main component - partially decomposed sphagnum moss organic debris [4]. The porosity ratio of this material is about $95 \%$, and the value of its specific surface area is usually greater than $200 \mathrm{~m}^{2}$ per $\mathrm{g}$ [5]. Furthermore, the biodegradation potential of peat is undeniable, and it also has other notable advantages, such as low cost and availability. Equally important, peat is a relatively environmentally friendly substance, which can also be included in the category of renewable resources. Due to these characteristics, peat could be recommended for the production of oil sorbents. Low hydrophobicity as well as relatively low sorption capacity and sorption velocity must be mentioned as the disadvantages of peat in this context. However, these properties can be improved through peat modification [6].

There are a number of methods known for the modification of natural biopolymers to increase their hydrophobicity [7]. Since peat is composed of hydrophilic (water-soluble and easily hydrolysable) and hydrophobic (bitumen, waxes) components, its hydrophobisation can be carried out by using its own hydrophobic components condensing on the surface of material as a result of thermal treatment [3]. The chemical hydrophobisation of peat can be achieved using water-repellent agents of organic or inorganic origin, for example, sodium salts of fatty acids, organosilicon substances, solutions of $\mathrm{Ca}^{2+}, \mathrm{Mg}^{2+}, \mathrm{Zn}^{2+}, \mathrm{Cu}^{2+}, \mathrm{Fe}^{2+}$ salts with carboxymethylcellulose additive and others [3]. Several known peat modification technologies include treatment at a temperature between $270^{\circ}$ and $300^{\circ} \mathrm{C}$ without air access [8], treatment with tar dissolved in solvents [9] and processing with ionic and non-ionic surfactant mixture [10]. However, there is still space for improving the sorptive properties of peat.

The aim of this study is to investigate the sorption of hydrocarbons on raised bog peat with different botanical composition and levels of decomposition, to determine the optimal conditions for the thermal treatment of peat as well as to study peat modification possibilities with the aim to increase its hydrophobicity, buoyancy and oil sorption characteristics using two chemical modification methods: methylation and silylation.

\section{MATERIALS AND METHODS}

\subsection{Materials}

Peat was obtained from a site of industrial peat extraction at Kaigu bog (Latvia). The peat used for this study has been well characterised in the previous studies [11], and its profile consists of consecutive peat layers with significantly differing botanical composition and levels of decomposition. Information about the degree of decomposition and botanical and elemental compositions of samples used is summarised in Table 1. All peat samples were milled to a particle size $0.2-2 \mathrm{~mm}$. In other experiments, only peat from sample No. 2 was used. 
Table 1: Characteristics of peat samples used

\begin{tabular}{|c|c|c|c|c|c|c|c|c|c|}
\hline \multirow{2}{*}{ No } & \multirow{2}{*}{$\begin{array}{l}\text { Average } \\
\text { embedding } \\
\text { depth }(\mathrm{cm})\end{array}$} & \multirow{2}{*}{$\begin{array}{c}\text { Botanical } \\
\text { composition }\end{array}$} & \multirow{2}{*}{$\begin{array}{c}\text { Age } \\
\text { (years) }\end{array}$} & \multirow{2}{*}{$\begin{array}{c}\text { Degree of } \\
\text { decomposition } \\
(\%)\end{array}$} & \multicolumn{5}{|c|}{ Elemental composition $(\%)$} \\
\hline & & & & & $\mathrm{C}$ & $\mathrm{H}$ & $\mathrm{N}$ & $\mathrm{S}$ & $\mathrm{O}$ \\
\hline 1 & 15 & $\begin{array}{l}\text { Cotton- } \\
\text { grass - } \\
\text { sphagnum } \\
\text { peat }\end{array}$ & 810 & 33 & 48.26 & 5.75 & 1,15 & 0.69 & 41.56 \\
\hline 2 & 35 & $\begin{array}{l}\text { Sphagnum } \\
\text { fuscum peat }\end{array}$ & 1200 & 10 & 49.31 & 5.75 & 0.84 & 1,01 & 43.39 \\
\hline 3 & 85 & $\begin{array}{c}\text { Narrow-leaf } \\
\text { sphagnum } \\
\text { peat }\end{array}$ & 1790 & 33 & 48.53 & 5.82 & 0.86 & 0.81 & 43.97 \\
\hline 4 & 110 & $\begin{array}{c}\text { Narrow-leaf } \\
\text { sphagnum } \\
\text { peat }\end{array}$ & 1970 & 7 & 48.53 & 5.58 & 0.77 & 0.72 & 44.44 \\
\hline 5 & 135 & $\begin{array}{l}\text { Sphagnum } \\
\text { fuscum peat }\end{array}$ & 2260 & 9 & 41.75 & 4.96 & 0.69 & 0.67 & 51.73 \\
\hline
\end{tabular}

Crude rapeseed oil with a density of $0.91 \mathrm{~g} / \mathrm{ml}$ was used as the hydrocarbon model substance to study the hydrocarbon sorption capacity on peats with different botanical compositions. Crude oil with a density of $0.81 \mathrm{~g} / \mathrm{ml}$ and a $42 \%$ content of volatile hydrocarbons was used for studying the interaction of modified products with hydrocarbons.

\subsection{Oil sorption capacity on peat with different botanical composition}

All peat samples were heated for 2 hours in a laboratory oven at $200^{\circ} \mathrm{C}$. Then $10 \mathrm{ml}(9.1 \mathrm{~g})$ of rapeseed oil and $1 \mathrm{~g}$ of peat were added into laboratory bottles (volume $100 \mathrm{ml}$ ) filled with 50 $\mathrm{ml}$ of MilliQ water. Samples were placed on a rotary shaker and shaken $(120 \mathrm{rpm})$ for 24 hours. After that samples were filtered through filter paper. The resulting mass (material with sorbed oil) was placed into $100 \mathrm{ml}$ bottles, treated with $20 \mathrm{ml}$ of acetone, extracted on the rotary shaker for 24 hours and then once again filtered through filter paper. The mass remaining on the filter was washed with $20 \mathrm{ml}$ of acetone. All the filtrates were placed in preweighed flasks and evaporated to a constant weight in the laboratory oven at $40^{\circ} \mathrm{C}$ temperature. Finally, the sorbed oil mass was estimated..

\subsection{TGA analysis of peat}

The optimal condensation temperature for the hydrophobic components of peat was determined using thermogravimetric analysis. The thermal analysis was performed with SII EXSTAR $6300 \mathrm{TG} / \mathrm{DTG}$ derivatograph within the temperature range of $25-550^{\circ} \mathrm{C}$ and heating rate of $10^{\circ} \mathrm{C} / \mathrm{min}$. The recorded curves were thermogravimetric (TG) and differential thermogravimetric (DTA). Thermograms were used for identifying the temperature region related to a rapid weight loss of the material (thermal degradation of peat structure). 


\subsection{Thermal treatment of peat}

Thermal treatment of peat was carried out in a laboratory oven: heating with unlimited air access - in the crucible, and heating with limited air access - in a closed steel cylinder with a $5 \mathrm{~cm}$ diameter and $40 \mathrm{~cm}$ length. Before heating, samples were moistened with water 1:1 by volume, to prevent the material from ignition. Heating was done in the temperature 240$250^{\circ} \mathrm{C}$. Heating times and sorption characteristics have been summarised in Table 4.

\subsection{Methylation of peat}

Samples of $10 \mathrm{~g}$ of peat were placed in an Erlenmeyer flask, adding $350 \mathrm{ml}$ of acetone and 0.1 mol $(12.61 \mathrm{~g})$ of dimethyl sulphate. Then the reaction mixture was heated with stirring on a magnetic stirrer, under condenser, at $50^{\circ} \mathrm{C}$. During the reaction 0.1 mole $(13.8 \mathrm{~g})$ of $\mathrm{K}_{2} \mathrm{CO}_{3}$ were added. Heating and stirring was continued for 10 hours. After that the reaction mixture was poured into 1 litre of MilliQ water, filtered, washed with water and a small amount of acetone. Methylation with the same amount of reagents was repeated three times. After treatment the sample was dried at $105^{\circ} \mathrm{C}$ for 5 hours.

\subsection{Silylation of peat}

$10 \mathrm{~g}$ of peat were placed in a 0.51 Erlenmeyer flask, adding $100 \mathrm{ml}$ of dichloromethane and 0.01 mole $(1.085 \mathrm{~g})$ of trimethylchlorosilane (Fluka). The reaction mixture was stirred on a magnetic stirrer without heating for 5 hours and then poured into 1 litre of MilliQ water, filtered, washed with water and dried at room temperature and at $105^{\circ} \mathrm{C}$ for 5 hours.

\subsection{Oil sorption experiment}

$4 \mathrm{ml}(3.23 \mathrm{~g})$ of pure oil and $0.25 \mathrm{~g}$ of peat sorbent were added into laboratory bottles (volume $100 \mathrm{ml}$ ) with $50 \mathrm{ml}$ of MillQ water. Samples were placed on a shaker and shaken at $120 \mathrm{rpm}$ for 5 hours. Then samples were filtered through filter paper. The resulting mass (peat with sorbed oil) was placed into laboratory bottles, treated with $20 \mathrm{ml}$ of hexane and extracted on the rotary shaker for 30 minutes, then once again filtered though filter paper. The mass collected on the filter was washed with $20 \mathrm{ml}$ of hexane. Pooled filtrate was placed in bottles with known mass and evaporated at room temperature to a constant weight. At the same time and in identical conditions, evaporated samples of oil with known mass were dissolved in hexane. The mass content of non-volatile hydrocarbons in the oil was calculated using mass difference. The sorbed oil mass was calculated using derived factor.

\subsection{Buoyancy evaluation}

Sorbent samples weighing $0.5 \mathrm{~g}$ were placed into laboratory bottles (volume $100 \mathrm{ml}$ ) with 50 $\mathrm{ml}$ of distilled water. The samples were left for 72 hours. Visual assessment of buoyancy by the criteria described below was made after 24,48 and 72 hours.

Criteria for the assessment of buoyancy:

5 points: All the material remains buoyant; part of the material is dry and floating.

4 points: A small portion of the material sunken, the remaining part is buoyant, mixed with water.

3 points: A significant part of the material sunken.

2 points: The most part of the material sunken.

1 point: All the material sunken. 


\subsection{Water sorption experiment}

Sorbent samples $(0.5 \mathrm{~g})$ were placed into laboratory bottles (volume $100 \mathrm{ml}$ ) with $50 \mathrm{ml}$ of distilled water, put on a rotary shaker and shaken at $120 \mathrm{rpm}$ for 5 hours. Then the samples were filtered through filter paper and weighed on analytical scales. The mass of sorbed water was calculated.

\subsection{Study of sorption kinetics}

$4 \mathrm{ml}(3.23 \mathrm{~g})$ of pure oil and $0.25 \mathrm{~g}$ of sorbent were added to laboratory bottles (volume 100 $\mathrm{ml}$ ) with $50 \mathrm{ml}$ of MilliQ water. The samples were placed on a rotary shaker, shaken at 120 rpm speed and removed after 2.5, 5, 10, 20, 30, 60, 120, 180, 240 and 300 minutes, filtering each sample afterwards. The sorbed oil was extracted with hexane, as described above. Finally, the mass of the sorbed oil was calculated.

\subsection{Characterisation of structural changes in the modified peat}

Fourier transform IR spectrometry was used for the characterisation of structural changes in the modified peat samples. It was carried out with Perkin Elmer Spectrum BX spectrometer. Infrared transmission spectra were taken as follows: peat samples were rubbed through a 0.25 $\mathrm{mm}$ sieve. $250 \mathrm{mg}$ of potassium bromide and $25 \mathrm{mg}$ of testable sample were weighed on the analytical scales. Then the sample was thoroughly mixed with potassium bromide and pressed in a special press into about a 1-mm-thick tablet. The tablet was inserted into the sample holder and the infrared spectrum was obtained.

\section{RESULTS AND DISCUSSION}

\subsection{Assessment of oil sorption capacity on peats with different botanical compositions}

The results of oil sorption experiment on peats with different botanical composition are presented in Table 2. As we see, a better sorption capacity is typical for Sphagnum fuscum peat with decomposition degree $\leq 10 \%$. So, the peat from sample No. 2 (sphagnum fuscum peat, with degree of decomposition $10 \%$ ) was chosen for further experiments.

Table 2: Oil sorption on peats with different botanical compositions

\begin{tabular}{cccc}
\hline № & $\begin{array}{c}\text { Botanical } \\
\text { composition }\end{array}$ & $\begin{array}{c}\text { Degree of } \\
\text { decomposition } \\
(\%)\end{array}$ & $\begin{array}{c}\text { Sorbed } \\
\text { oil } \\
(\mathrm{g} / \mathrm{g})\end{array}$ \\
\hline 1 & $\begin{array}{c}\text { Cotton grass, } \\
\text { sphagnum }\end{array}$ & 33 & 3.48 \\
\hline 2 & Sphagnum fuscum & 10 & 5.98 \\
\hline 3 & $\begin{array}{c}\text { Narrow-leaf } \\
\text { sphagnum }\end{array}$ & 33 & 3.52 \\
\hline 4 & $\begin{array}{c}\text { Narrow-leaf } \\
\text { sphagnum }\end{array}$ & 7 & 4.17 \\
\hline 5 & Sphagnum fuscum & 9 & 5.16 \\
\hline
\end{tabular}




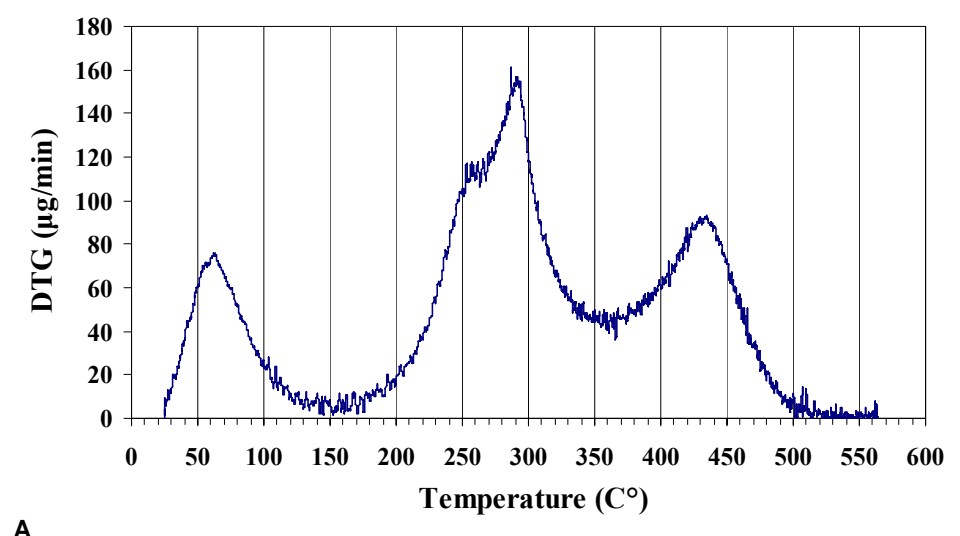

A

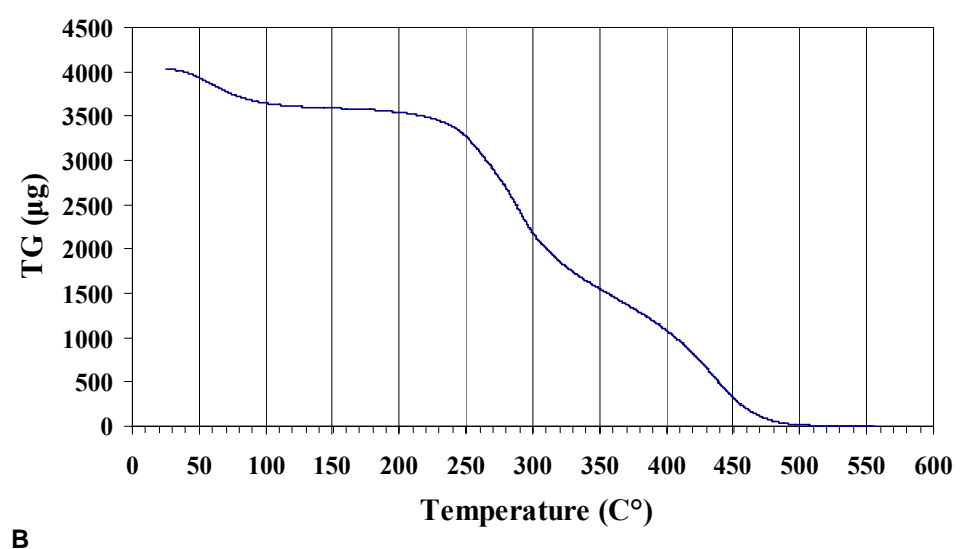

Figure 1. TG and DTG curves representing thermal degradation of raw peat

\subsection{Conditions of the thermal treatment of peat}

Figure 1 shows the results of thermogravimetric analysis of raw peat. After the evaporation of water at a temperature range around $100^{\circ} \mathrm{C}$, the TG curve shows a tendency to straighten out, while the DTG curve shows a significant reduction of the mass loss, and this fact indicates that no significant changes in the structure or composition of the studied peat samples have taken place at the temperature range between 100 and $200^{\circ} \mathrm{C}$. The increase of mass loss is observed at the temperature range between 200 and $250^{\circ} \mathrm{C}$, and this process cannot be associated with the destruction of aromatic structural units of peat, which occurs at much higher temperature [12]. Probable it can be assumed that, at this temperature interval, the volatile peat components evaporate, while the less volatile compounds start to condensate. At the temperature range between 250 and $275^{\circ} \mathrm{C}$, we can observe a decrease in weight loss, which is indicative of an active condensation process of hydrocarbons on the surface of the material. At a temperature higher than $275^{\circ} \mathrm{C}$, we can observe a rapid mass loss, indicating a rapid destruction of hydrocarbons and substances forming the structure of peat. These results show that the temperature for thermal condensation of hydrocarbons without the loss of 
material structure in aerobic conditions should definitely be higher than $200^{\circ} \mathrm{C}$, but should not exceed $275^{\circ} \mathrm{C}$.

It is possible that in anaerobic conditions the optimal temperature for thermal treatment could be higher than $275^{\circ} \mathrm{C}$ because of the reduced impact of oxygen and weaker oxidative destruction. This confirms the information provided in [10], i.e. that temperature for thermal hydrophobisation of peat in anaerobic conditions can be within the range of $270-300^{\circ} \mathrm{C}$; however, in our opinion, the lower limit of this temperature range should be slightly lower, and the optimal temperature range for thermal hydrophobisation of peat is from 230 to $300^{\circ} \mathrm{C}$. A temperature range between 240 and $250^{\circ} \mathrm{C}$ was chosen for our experiments.

\subsection{Thermal treatment of peat and characterisation of resulting structural changes}

Structural changes resulting from thermal treatment of peat have been studied using FTIR spectroscopy. FTIR spectrograms of raw peat and heated peat samples are showed in Figure 2. As we can see, the spectrum of raw material contains absorption peaks that are typical for peat:

- The peak at a wavelength within the range 3300-3400 (centred at 3360) indicates the stretching of $\mathrm{O}-\mathrm{H}$ bonds and the presence of the hydroxyl groups in phenols, alcohols and carbohydrates;

- The peak at a wavelength within the range 2490-2900 (centred at 2890) indicates the stretching of $\mathrm{C}-\mathrm{H}$ bonds and the presence of aliphatic $\mathrm{CH}$ chain fragments in the macromolecular structure of the material;

- The peak at a wavelength within the range 1720-1725 (centred at 1721) indicates the stretching of $\mathrm{C}=\mathrm{O}$ bond and the presence of carbonyl functional groups;

- The peak at a wavelength beyond the range 1600-1620 (centred at 1602) indicates the stretching of cyclic $\mathrm{C}=\mathrm{C}$ bonds and the presence of aromatic rings;

- The peak at a wavelength within the range 1170-950 (centred at 1025) indicates the stretching of $\mathrm{C}-\mathrm{O}$ bonds in carbohydrates and the presence of polysaccharides.

Similar peaks can be observed in the IR spectra of the heat-treated samples. Notably, as we can see, the intensity of peaks varies, and there is a complete disappearance of some peaks in the spectra of samples heated with unlimited air access. These results indicate that significant changes have occurred as a result of thermal treatment. For a quantitative characterisation of the abovementioned changes, it is necessary to compare the spectral transmission factors. For this purpose, we have chosen the following factors of spectral transmission:

- The ratio between transmission values at wavelengths 3360 and 2890, describing the relation between the content of hydroxyl-bonded functional groups and the content of aliphatic hydrocarbons;

- The ratio between transmission values at wavelengths 3360 and 1602, describing the relation between the content of hydroxyl-bonded functional groups and the content of aromatic skeleton-forming compounds;

- The ratio between transmission values at wavelengths 2890 and 1602 , describing the relation between the content of aliphatic hydrocarbons and the content of aromatic skeleton-forming compounds;

- The ratio between transmission values at wavelengths 1721 and 1602 , describing the relation between the content of carbonyl functional groups and the content of aromatic skeleton-forming compounds; 
- The ratio between transmission values at wavelengths 1025 and 1602 , describing the relation between the content of polysaccharides and the content of aromatic skeletonforming compounds

Table 3: Values of spectral transmittance factors for samples heated with limited air access

\begin{tabular}{lccccc}
\hline Sample $\downarrow$ Factor $\rightarrow$ & $\begin{array}{c}\mathrm{OH}_{3360} / \\
\mathrm{C} \mathrm{H}_{2890}\end{array}$ & $\begin{array}{c}\mathrm{OH}_{3360} / \\
\mathrm{C}=\mathrm{C}_{1602}\end{array}$ & $\begin{array}{c}\mathrm{C}-\mathrm{H}_{2890} / \\
\mathrm{C}=\mathrm{C}_{1602}\end{array}$ & $\begin{array}{c}\mathrm{C}=\mathrm{O}_{1721} / \\
\mathrm{C}=\mathrm{C}_{1602}\end{array}$ & $\begin{array}{c}\mathrm{C}-\mathrm{O}_{1025} / \\
\mathrm{C}=\mathrm{C}_{1602}\end{array}$ \\
\hline Raw peat & 0.36 & 0.25 & 0.69 & 0.98 & 0.35 \\
\hline Heated for 4 hours & 0.30 & 0.16 & 0.55 & 1.00 & 0.35 \\
\hline Heated for 6 hours & 0.49 & 0.47 & 0.97 & 1.25 & 0.84 \\
\hline Heated for 10 hours & 0.67 & 0.58 & 0.87 & 1.25 & 1.35 \\
\hline
\end{tabular}

The values of the abovementioned factors for the samples that were heated with limited air access are summarised in Table 3.

IR spectra of the modified samples show the degradation of oxygen-containing material in the peat structure as a result of heat treatment. $\mathrm{OH}_{3360} / \mathrm{C}-\mathrm{H}_{2890}$ and $\mathrm{OH}_{3360} / \mathrm{C}=\mathrm{C}_{1602}$ factor indicates a slight increase in the content of hydrogen-bonded $\mathrm{OH}$ groups after a 4-hour long heating period with limited air access. This phenomenon can most likely be explained with the influence of water vapour, and its occurrence is related with experimental conditions. Later on, a significant decrease in the content of hydroxyl groups was observed. In the spectra of samples heated with unlimited air access, we can see the disappearance of the $\mathrm{OH}_{3360}$ peak after 4 hours of heating, indicating complete removal of hydrogen-bonded hydroxyls. The increase in $\mathrm{OH}_{3360} / \mathrm{C}=\mathrm{C}_{1602}$ together with the increase of $\mathrm{C}-\mathrm{O}_{1025} / \mathrm{C}=\mathrm{C}_{1602}$ taking place after 6 hours of heating with limited air access indicates the thermal destruction of hydrophilic polysaccharides, while the increase of $\mathrm{OH}_{3360} / \mathrm{C}=\mathrm{C}_{1602}$ value together with the increase of $\mathrm{C}=$ $\mathrm{O}_{1721} / \mathrm{C}=\mathrm{C}_{1602}$ points at the destruction of $\mathrm{COOH}$ functional groups.

The decrease of $\mathrm{C}-\mathrm{H}_{2890} / \mathrm{C}=\mathrm{C}_{2602}$ value after a 4-hour long heating period with limited air access indicates an increase in the relative amount of aliphatic chains in the material as well as the condensation of hydrocarbons on the surface of the material. However, when the heating time exceeds 4 hours, we can observe a rapid increase of $\mathrm{C}-\mathrm{H}_{2890} / \mathrm{C}=\mathrm{C}_{2602}$ value, which is common in the case of oxidation of hydrocarbons under the influence of atmospheric oxygen. The impact of oxygen on the destruction of aliphatic chains is also observed in the spectra of peat heated with unlimited air access, where the $\mathrm{C}-\mathrm{H}_{2890}$ peak disappears already after 4 hours of heating. In our opinion, the inconsequence in the increase of value of $\mathrm{C}-\mathrm{H}_{2890} /$ $\mathrm{C}=\mathrm{C}_{1602}$ indicates that the condensation and degradation of aliphatic compounds take place simultaneously.

\subsection{Characterisation of application possibilities of the modified peat samples}

The results of experimental evaluation of raw peat and the modified peat samples are summarised in Table 4. The curves of oil sorption kinetics on the modified materials as well 
as on raw peat are shown in Figure 3. As we see, some properties of peat can be significantly improved by heating and methylation, while the improvement of properties resulting in silylation is not sufficient for all indicators, except the water sorption capacity.

Heating with unlimited air access can improve the hydrophobic and oleophilic properties of peat after a 4-hour period long treatment, whereas longer heating deteriorates the characteristics achieved by heating the material for up to 4 hours. As we can see in Figure 2(A), the improvement of characteristics in this case can be explained by the destruction of oxygen-containing polysaccharides and carboxyl groups within the structure of the material. This process can reduce the polarity of substance and improve its oleophilic properties accordingly. However, as we can see in Table 4, such treatment is associated with a rapid, irreversible loss of mass and, accordingly, the structure of peat. In our opinion, despite the fact that our results indicate the possible effectiveness of 4-hour long peat heating with unlimited air access for the improvement of its oil sorption characteristics, this method is not the best for this purpose. As we see, much better results can be obtained by heating with limited air access. In this case, a sufficient improvement of properties can be observed after 4-

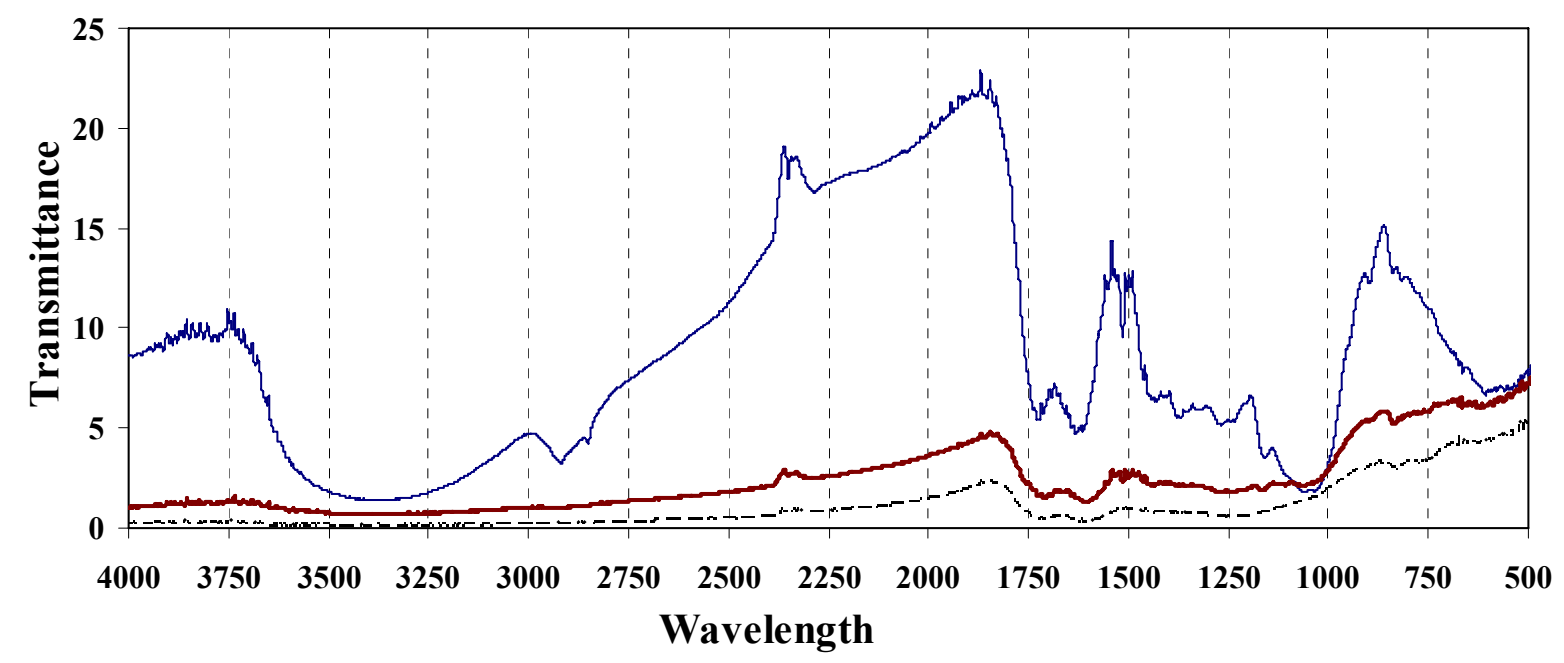

A

Raw peat ---- Heated for 4 hours $\longrightarrow$ Heated for 6 hours 
Linnaeus ECO-TECH '10

Kalmar, Sweden, November 22-24, 2010

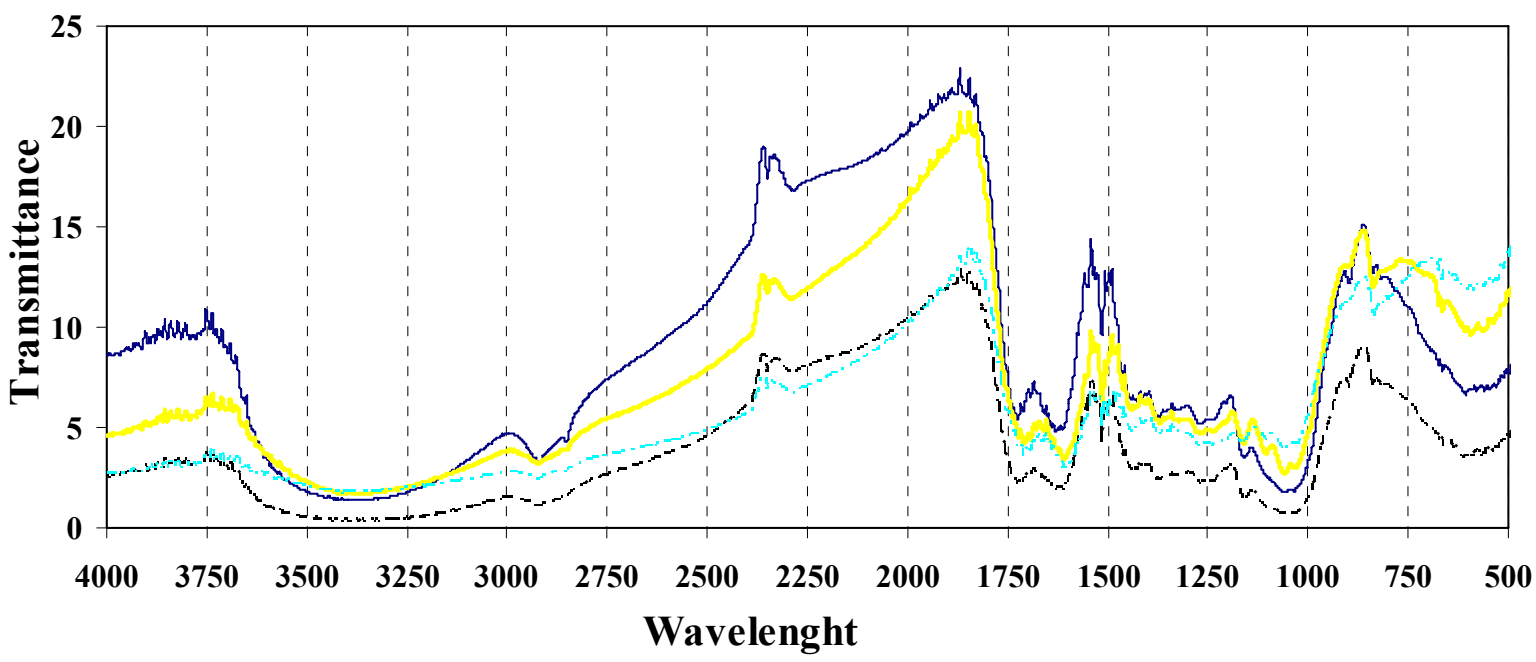

B — Raw peat ---- Heated for 4 hours $\longrightarrow$ Heated for 6 hours $\cdots-\cdot$ Heated for 10 hours

Figure 2: FTIR spectra of thermally treated peat samples in the presence of air (A) and in limited air access conditions $(B)$. 


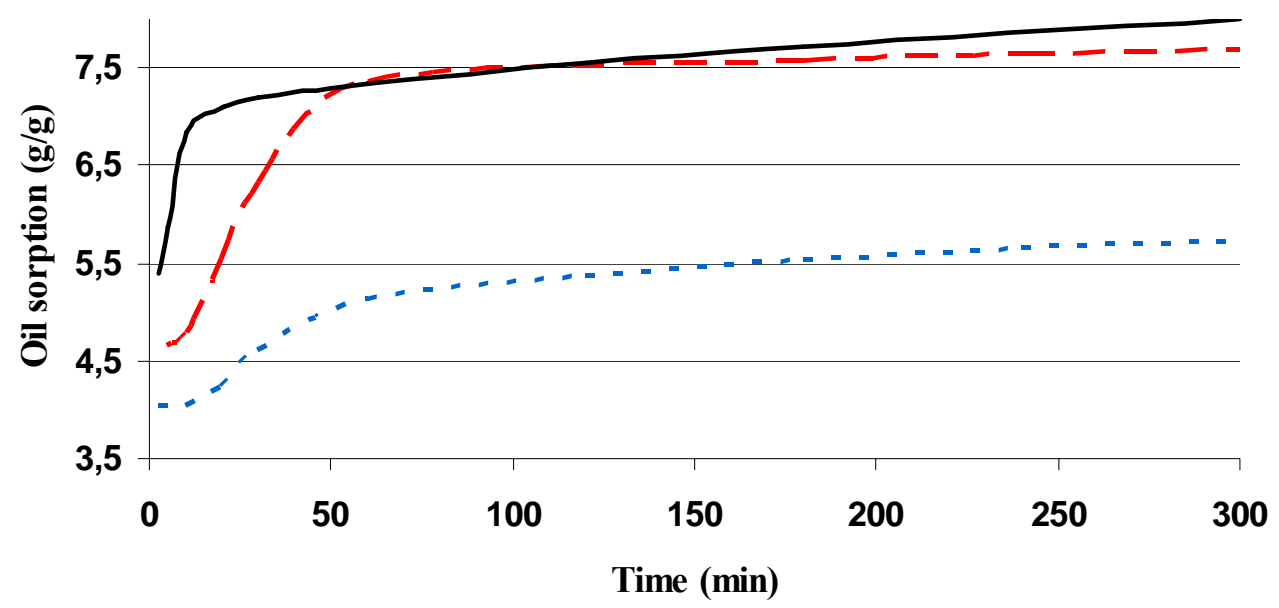

A - - - Raw peat - - Peat heated for 4 hours $\longrightarrow$ Peat heated for 10 hours

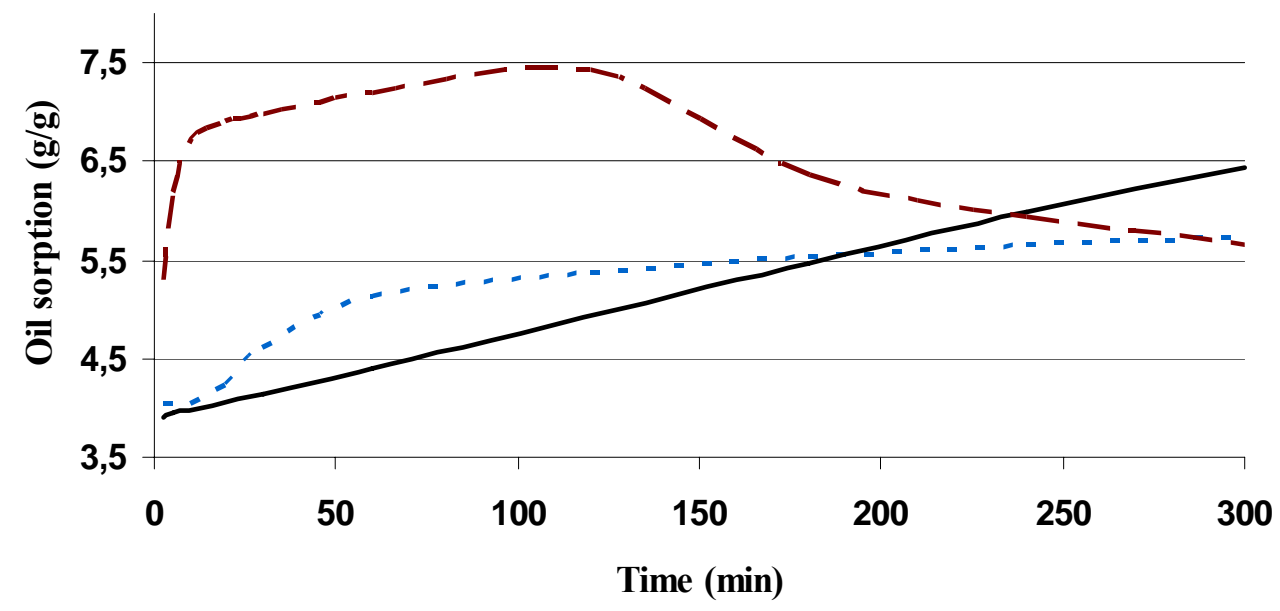

B $\quad-\cdots$ Raw peat $\longrightarrow$ Silanised peat -- Methilated peat

Figure 3: Curves of oil sorption kinetics on heated peat samples (A) and on chemically modified peat samples (B).

hours long heating, while the best results can be obtained by 6-8 hours long heating. In our view, all changes of properties in this case can not be explained only with condensation of aliphatic hydrocarbons. As we can see, the sample with the lowest value of $\mathrm{C}-\mathrm{H}_{2890} / \mathrm{C}=\mathrm{C}_{1602}$ factor shows only the lowest value of water sorption, but not the best result in oil sorption. Later on, we can observe a continued increase in the oil sorption capacity in spite of the decrease in the $\mathrm{C}-\mathrm{H}_{2890} / \mathrm{C}=\mathrm{C}_{1602}$ factor. It can be explained with the destruction of oxygencontaining structural fragments of the material. Figure 3 (A) shows that thermal treatment affects the sorption capacity of peat as well as oil sorption kinetics. This phenomenon can also be explained with the depletion of oxygen-containing structural fragments and the resultant 
changes in the polarity of material. The destruction of oxygen-containing compounds, in contrast to the destruction of aliphatic compounds, is not related to the presence of oxygen. It means that complete prevention of oxygen access in the process of heating may be the optimal solution for thermal production of peat sorbents.

As we can see in Table 4 and Figure 3, the silylation of peat is not the most efficient method for the improvement of its sorption properties, as the only improvement that can be achieved in this case is a decrease in water sorption capacity, but it is not enough for a good oil sorbent. In the case of methylation, the improvement of properties is more satisfactory. The methylated sample shows a very low water sorption and a relatively good buoyancy; however, it does not show good oil sorption properties. As we see in Figure 3 (B), such a result is not related to the lack of sorption; instead, it is related to the instability of it. The desorption of the sorbed oil that takes place after 2 hours can not be explained without the data about structural changes in the methylated peat. Nevertheless, the presence of this phenomenon itself allows at least to suggest that this method is not as good for the improvement of sorption characteristics of peat compared to the treatment with heat. Moreover, these results also indicate that this method could be effective if it was possible to prevent the phenomenon of desorption. It means that further research in this direction is in order.

\section{CONCLUSIONS}

This study has confirmed that the initial sorption characteristics of peat can be significantly improved for the production of peat-based oil sorbents. Sphagnum fuscum peat with low $(10 \%)$ degree of decomposition showed the best initial sorption capacity in our study. We have found that the optimal heating conditions for thermal modification of peat are 6-8 hours long heating in anaerobic environment at the temperature range between 230 and $280^{\circ} \mathrm{C}$.

Our study demonstrated that the improvement of peat sorption characteristics as a result of heat treatment can be explained not only with the condensation of aliphatic hydrocarbons on the surface of the material but also with the destruction of oxygen-containing fragments in the macromolecular structure of peat. Furthermore, we have found that the condensation of aliphatic hydrocarbons affects the water sorption capacity more than other characteristics, while the increase in oil sorption capacity and sorption velocity are induced by the depletion of oxygen-containing compounds.

The methods of chemical treatment of peat which were used in this study (methylation and silylation) were less effective for the improvement of sorption properties of a peat than thermal treatment. However, our study has also shown that the methylation of peat may be an effective method of modification if it is possible to make the oil sorption on the methylated material more stable. Consequently, we believe that it is worthwhile to continue the work on the characterisation and development of this method. On the other hand, the results of silylation show that it is relatively unlikely that good results in the modification of peat sorption properties can be reached using this method. 
Table 4: Properties of investigated samples

\begin{tabular}{|c|c|c|c|c|c|c|}
\hline \multirow{2}{*}{ Sample } & \multirow{2}{*}{$\begin{array}{l}\text { Weight } \\
\text { loss }(\%)\end{array}$} & \multirow{2}{*}{$\begin{array}{c}\text { Water } \\
\text { sorption } \\
(\mathrm{g} / \mathrm{g})\end{array}$} & \multicolumn{3}{|c|}{ Evaluation of buoyancy } & \multirow{2}{*}{$\begin{array}{c}\text { Oil } \\
\text { sorption } \\
(\mathrm{g} / \mathrm{g})\end{array}$} \\
\hline & & & $24 \mathrm{~h}$ & $48 \mathrm{~h}$ & $72 \mathrm{~h}$ & \\
\hline Raw peat & - & 10.5 & 3 & 2 & 2 & 5.8 \\
\hline \multicolumn{7}{|c|}{ Peat samples heated with unlimited air access } \\
\hline $\begin{array}{l}\text { Heated for } \\
30 \text { minutes }\end{array}$ & No data & 8.9 & 3 & 2 & 2 & 6.9 \\
\hline $\begin{array}{l}\text { Heated for } \\
1 \text { hour }\end{array}$ & No data & 9.6 & 4 & 4 & 3 & 5.8 \\
\hline $\begin{array}{l}\text { Heated for } \\
2 \text { hours }\end{array}$ & No data & 7.8 & 4 & 4 & 3 & 5.7 \\
\hline $\begin{array}{c}\text { Heated for } \\
4 \text { hours }\end{array}$ & 48 & 7.9 & 5 & 5 & 5 & 8.5 \\
\hline $\begin{array}{l}\text { Heated for } \\
6 \text { hours }\end{array}$ & 72 & 7.6 & 4 & 4 & 4 & 7.3 \\
\hline \multicolumn{7}{|c|}{ Peat samples heated with limited air access } \\
\hline $\begin{array}{c}\text { Heated for } \\
2 \text { hours }\end{array}$ & No data & 6.0 & 4 & 3 & 2 & 5.9 \\
\hline $\begin{array}{c}\text { Heated for } \\
4 \text { hours }\end{array}$ & 23 & 6.2 & 5 & 5 & 5 & 7.4 \\
\hline $\begin{array}{l}\text { Heated for } \\
6 \text { hours }\end{array}$ & 29 & 6.2 & 5 & 5 & 5 & 8.2 \\
\hline $\begin{array}{l}\text { Heated for } \\
8 \text { hours }\end{array}$ & 40 & 6.5 & 5 & 5 & 5 & 8.6 \\
\hline $\begin{array}{c}\text { Heated for } \\
10 \text { hours }\end{array}$ & 52 & 6.7 & 5 & 5 & 5 & 8.6 \\
\hline \multicolumn{7}{|c|}{ Silanised peat sample } \\
\hline PeatTmSil & $\begin{array}{c}\text { Not } \\
\text { observed }\end{array}$ & 7.0 & 4 & 3 & 3 & 6.6 \\
\hline \multicolumn{7}{|c|}{ Methylated peat sample } \\
\hline PeatMe & $\begin{array}{c}\text { Not } \\
\text { observed }\end{array}$ & 4.3 & 5 & 5 & 4 & 5.7 \\
\hline
\end{tabular}

\section{REFERENCES}

1. Oil in the Sea III: Inputs, Fates, and Effects 2002. National Research Council, Committee on Oil in the Sea: Inputs, Fates, and Effects. National Academies Press: Washington DC. p. 28

2. Adebajo M. O., Frost R. L., Kloprogge J. T., Carmody O. 2003 Porous materials for oil spill cleanup: a review of synthesis and absorbing properties. Journal of Porous Materials 10: pp. 159-170.

3. Novosolova L., Sirotkina E. 2008 Peat based sorbents for treatment of polluted environments (review). Chemistry of Solid Fuel 4: pp. 64-77 (in Russian).

4. Turemnov S. 1974 Peat Deposits. Third edition revised and enlarged. Nedra, Moscow. (in Russian). 
5. Encyclopedia of Surface and Colloid Science 2004. Ed. by Somasundaran P. Update Supplement. New York, Taylor \& Francis.

6. Burmistrova T., Alekseeva T., Stahina L., Seredina V., 2009. Investigation of the properties of peat for environmental solutions. Chemistry of Plant Origin Materials 3, pp. 157-160 (in Russian).

7. Bledzki A.K., Sperber V.E., Faruk O. 2002 Methods of Surface Treatment of Natural and Wood Fibres. Natural and Wood Fibre Reinforcement in Polymers: Smithers Rapra, pp. 15-19.

8. Gridin O., Gridin S., Muratov V., Muratov, E., 2003. Method for producing a hydrophobic sorbent. Russian Federation Patent 2214859.

9. Knatko V., Knatko M., 2003. Sorbent for purification of polluted environments. Russian Federation patent 2209113.

10. Gavrin A., Nesterov Y., Filimonov O., Karasev A., 1999. Sorbent for cleaning of waters, polluted with oil and petroleum products. Russian Federation patent 2126714.

11. Shire J., 2010. Composition and properties of humic acids in raised bog peat. Thesis for doctor's degree in environmental science: Riga: University of Latvia Publishing House.

12. Klavins M., Ansone L., Tjutrins J., Silamikele I., Purmalis O. 2010. Differential thermal analysis of peat and peat humic acids in relation to their origin. Mires and Peat: Riga, University of Latvia Press, pp. 207-214. 